\title{
Canal anatomy modifications by using path files, glide path instruments analysed by Cone Beam Computed Tomography
}

\author{
Anil Dhingra ${ }^{1}$, Nayasha Manchanda ${ }^{2}$ \\ ${ }^{I}$ (Department Of Conservative Dentistry and Endodontics, DJ College of Dental Sciences and Research, \\ Modinagar, Uttar Pradesh / B.R. Ambedkar University, Agra, India) \\ ${ }^{2}$ (Department Of Conservative Dentistry and Endodontics, DJ College of Dental Sciences and Research, \\ Modinagar, Uttar Pradesh / B.R. Ambedkar University, Agra, India)
}

\begin{abstract}
The aim of this study was to describe canal anatomy modifications by Path Files (PF) using cone beam computed tomography (CBCT) in mandibular first molars. A total of 100 mesiobuccal (MB) root canals of mandibular first molars were prepared with PF. CBCT was used to scan the specimens before and after instrumentation. The root canal curvature, centric ability, apical transportation, root canal cross sectional area and canal volume were measured. Changes in canal anatomy modifications were recorded at $0,1,2,3,5$ and $7 \mathrm{~mm}$ intervals. There was a statistical difference in the root canal curvatures between the pre and post instrumented samples $(P<0.05)$. There was no transportation at $5 \mathrm{~mm}$, all the canals were transported towards the distal side except there was a slight mesial transportation at $0 \mathrm{~mm}$. They exhibited good centric ability at all the intervals except at $1 \mathrm{~mm} \quad(P>0.05)$. The difference in the cross sectional area was also statistically significant at all the intervals $(P<0.05)$. The changes in the volume were statistically significant at all the intervals except at $3 \mathrm{~mm}(P>0.05)$.
\end{abstract}

Keywords: Apical Transportation, Canal Volume, Centric Ability, Root Canal Cross-Sectional Area, Root Canal Curvature.

\section{Introduction}

There are two objectives of root canal preparation : thorough debridement of the canal system, shaping of the canal and creation of a continuously tapered funnel form with the widest diameter at the canal orifice and the smallest diameter at the apical terminus, respecting the original shape of the canal. This "ideal" preparation is difficult to achieve in curved root canals or S-shaped canals, especially with stainless steel hand instruments. [1-2].

The introduction of nickel-titanium [NiTi] alloys has revolutionized root canal preparation $[3,4,5,6]$. But these instruments are subjected to structural fatigue that eventually leads to failure [7,8], mainly because of bending normal stresses [failure by fatigue] and torsional shear stresses [failure by torque] $[9,10]$. Fracture due to flexural fatigue [bending stress] occurs when an instrument that has already been weakened by metal fatigue is placed under stress. The instrument does not bind to the root canal walls but rotates freely until fracture of the instrument occurs at the point of maximum flexure $[11,12]$. Torsional fracture occurs when the tip, or any other part of the rotating instrument, binds to the root canal walls while the rest of the file keeps turning. This happens when the operator exerts too much apical force on the rotating instrument in the root canal [13]. There is a wide area of contact between the cutting flutes of the instrument and the canal walls, or if the canal section is smaller than the dimension of the non-cutting or non-active tip of the instrument $[14,15]$. The end result would be that the elastic limit of the metal is exceeded and fracture of the file occurs [16].

The endodontic glidepath is a smooth radicular tunnel from canal orifice to the physiologic terminus [foraminal constriction]. The minimal size should be a "super loose No. 10" endondontic file. Glide path creation is essential for prevention of rotary file separation and most effective rotary use. It is necessary for quality control. The lack of glide path establishment and glide path enlargement is often the cause of ledge formation, transportation, blockage of root canals followed by obturation which is short of the apical constricture [17]. Blending a hand created glide path with the .02 tapered 15 and 20 tip sized K3 to facilitate subsequent rotary use can be an important adjunct in this endeavour [18].

The PF consist of three rotary instruments with the following characteristics :

Tip diameter: the tip diameter for the three PF is $0.13,0.16$ and $0.19 \mathrm{~mm}$, respectively. The gradual increase of the tip diameter [less than $30 \%$ ] facilitate the progression of the files without need of using strong axial pressure. The tip is rounded and not cutting to avoid ledging and zip. They have a square cross section. It is easy to manufacture, robust cross section increases the resistance of PF to torsional stresses nevertheless their small diameter and taper. The four cutting angles increase the efficacy of PF even in calcified and long canals. The distance between two following blades has been optimize to increase the strength of the instruments. PF are 
manufactured with a NiTi alloy. The flexibility is enhanced by the low .02 taper of the files that is also responsible of the high resistance of the PF to flexural stresses.

In order to be safe, before rotary shaping, the dentist must always discover that a glide path already exists or that one needs to be created [19].

The advent of 3D imaging has provided the endodontist with tools that were not available before. It has facilitated interactive image manipulation and enhancement to visualize the area of interest as a 3D volume. Cone Beam Computed Tomography [CBCT] has provided with a significantly faster image acquisition and reconstruction scheme and also it aids in the diagnosis of canal morphology [20, 21].

When compared with conventional periapical radiography, CBCT eliminates superimposition of surrounding structures, providing additional clinically relevant information [22]. Its resolution is not as high as that of conventional radiographs, but the availability of 3Dimensional information and a relatively higher resolution and a significantly lower dose than medical-grade Computed Tomography makes CBCT the imaging modality of choice in challenging situations which demands localization and characterization of root canals [21].

\subsection{Selection and Specimen preparation}

\section{Materials and methods}

Hundred periodontally involved and caries free mandibular first molars were selected from a pool of extracted teeth for the present study. After extraction they were stored in $0.01 \%$ sodium hypochlorite $(\mathrm{NaOCl})$. Only teeth with intact and mature root apices were included in the study. Inclusion criteria stipulated that the tooth had a curved MB root canal with curvature angles ranging within $20-40^{\circ}$ (Schneider 1971). Standardized radiographs were taken in a buccal-lingual and mesiodistal dimension before the instrumentation. The specimens had been placed in a radiographic mount made of a silicone-based impression material (Aquasil Ultra; Dentsply International, New York, NY) so that a constant position could be obtained.

This mount was positioned on a radiographic-paralleling device. The radiographs in the buccal-lingual dimension were taken to confirm the presence of two distinct and separate root canals. In the mesiodistal dimension, $\mathrm{K}$ files no. 10 were inserted into the buccal canal to assess the degree of root canal curvatures according to Schneider's technique. Coronal access was achieved by using Endo-Access and Endo-Z burs (Dentsply Maillefer, Ballaigues, Switzerland) to obtain a straight line access. Each tooth was sectioned through the furcation and the mesial portion of the root and crown was used. Distal roots with the respective part of the crown were sectioned at the furcation level and discarded. All mesial root canals were controlled for apical patency with a K-File no. 10 (Dentsply Maillefer, Ballaigues, Switzerland). Working length was set $1 \mathrm{~mm}$ from the apical foramen was taken using K-File no. 10 (Dentsply Maillefer, Ballaigues, Switzerland). Periapical radiographs were recorded to confirm the working length.

\subsection{Preinstrumented Specimen Scanning}

Roots were embedded into transparent acrylic (Orthoplast, Zeist, Netherlands). All teeth were scanned by Cone Beam Computed Tomography (CBCT). The sections were $0.9 \mu \mathrm{m}$ thick from apical to the canal orifice. All cross-section images (uninstrumented and instrumented) were studied at distances $0,1,2,3,5$ and 7 $\mathrm{mm}$ from the most apical point of each specimen.

\subsection{Root canal instrumentation}

A new sequence of files was used for each canal. Coronal flaring was done in the MB canals using Protaper SX file (Dentsply Maillefer, Ballaigues, Switzerland) at $350 \mathrm{rpm}$ in a brushing motion using the manufacturer's guidelines. All the canals were prepared using torque control motor (X-Smart, Dentsply Maillefer, Ballaigues, Switzerland) with a $16: 1$ reduction ratio contra-angle handpiece.

The canals were prepared in the sequence PF $1(0.13 \mathrm{~mm})$, PF $2(0.16 \mathrm{~mm})$, PF $3(0.19 \mathrm{~mm})$ in continuous rotation to the working length. All PF were utilized with a rotation speed of $300 \mathrm{rpm}$, a motor torque of approximately $3 \mathrm{~N} / \mathrm{cm}$ and with delicate in/out movements until they reach the full length. Copious irrigation with $2 \mathrm{ml}$ of distilled water was performed after the use of each rotary file by a 27-G irrigation needle.

\subsection{CBCT scanning and measurements}

Roots were embedded into transparent acrylic (Orthoplast, Zeist, Netherlands). All the teeth were scanned pre- and postoperatively in the high resolution dental mode (i.e. 90 micron resolution). The setting for the CBCT scanner was $84 \mathrm{kVp}$ and $5 \mathrm{~mA}$. All the scans were reoriented with respect to the $\mathrm{x}-, \mathrm{y}-\mathrm{and} \mathrm{z}$-axes, using the imaging software CS9300 equipment (Carestream Healthcare India (P) Ltd). Study images were reconstructed from the volumetric dataset, in planes perpendicular to the selected tooth axes. The transportation, centric ability, surface area and volume of the root canals were evaluated at 0.0 (Fig. 1A), 1.0 (Fig. 1B) , 2.0 (Fig. 1C), 3.0 (Fig. 1D), 5.0 (Fig 1E), and 7.0 (Fig. 1F) mm intervals. The pre and post instrumentation images were superimposed using G.I.M.P 2.8.4 software (Fig. 2B). 
Canal anatomy modifications by using path files, glide path instruments analysed by Cone Beam

\subsubsection{Measurement of root canal curvature}

The curvature of the MB canals was measured according to Schneider 1971 in the transverse axis (Fig. 2A)

\subsubsection{Measurement of cross sectional area}

The radius of the pre- and postoperative images was calculated in the axial sections at the various intervals. The area was calculated using the formula $\pi r^{2}$.

\subsubsection{Measurement of volume}

Using the MicroView 3-D volume viewer and analysis software, images of the canals before and after instrumentation were inverted and not superimposed to assess the volume. The volume at each interval of the canal could be calculated before and after instrumentation. The mean changes in these parameters were determined by subtracting the scores for the instrumented canals from those recorded for the uninstrumented canals (Fig. 2C).

\subsubsection{Measurement of canal transportation}

The pre- and post-instrumentation scans were superimposed to allow canal transportation in and centring ability to be determined. The dimensions were determined by measuring the shortest distance from the edge of the uninstrumented canal to the edge of the tooth in both mesial (m1) and distal (d1) directions and then compared with the values measured from the prepared canals ( $\mathrm{m} 2$ and $\mathrm{d} 2$ ).

The following formula (1) was used for the calculation of transportation:

$(\mathrm{d} 1-\mathrm{d} 2)-(\mathrm{m} 1-\mathrm{m} 2)(1)$

A result of zero indicated no canal transportation; a positive result indicated transportation towards the furcal (distal) aspect of the root; a negative result indicated transportation towards the mesial aspect of the root.

\subsubsection{Measurement of centring ability}

This ratio (2) was calculated for each section using the following formula:

$(\mathrm{d} 1-\mathrm{d} 2) /(\mathrm{m} 1-\mathrm{m} 2)$ or $(\mathrm{m} 1-\mathrm{m} 2) /(\mathrm{d} 1-\mathrm{d} 2)(2)$

Gambill et al. (1996) defined centring ratio as the measurement of the ability of the instrument to stay centred in the canal.

The numerator for this formula was the smaller of the two numbers, if these numbers were unequal. A result of one indicated perfect centring ability; the closer the result is to zero, the worse the ability is of the instrument to remain centred.

\section{Statistical analysis}

Non parametric Chi-square test was performed to detect the significant differences in relation to canal transportation and centric ability at the various intervals. Paired t-test was applied to calculate the mean difference and standard deviation in root canal curvature, cross sectional area and volume. The level of significance was set at alpha $=0.05$.

\subsection{Root canal curvature}

\section{Results}

There was a statistical difference in the root canal curvatures between the pre and post instrumented samples $(\mathrm{P}<0.05)$. The mean changes are shown in Table 1, (Fig. 3A).

\subsection{Canal Transportation}

There was no transportation at $5 \mathrm{~mm}$, all the canals were transported towards the distal side except there was a slight mesial transportation at $0 \mathrm{~mm}$. The overall results indicated the difference statistically significant at all the intervals $(\mathrm{P}<0.05)$. The values are shown in Table 1, (Fig. 3B).

\subsection{Centric ability}

PF exhibited good centric ability at all the intervals except at $1 \mathrm{~mm}(\mathrm{P}>0.05)$. The values are shown in Table 1, (Fig. 3C). 


\subsection{Cross sectional area}

The increase in cross sectional area when compared between pre and post instrumented samples was statistically significant at all the intervals $(\mathrm{P}<0.05)$. The changes are shown in Table 1, (Fig. 3D).

\subsection{Volume}

The change in the volume was statistically significant at all the intervals except at $3 \mathrm{~mm}(\mathrm{P}>0.05)$. The changes are shown in Table 1, (Fig. 3E

\section{Discussion}

The first phases of canal instrumentation during which the clinician might more frequently find procedural difficulties are canal scouting and preflaring (23). For safer use of NiTi rotary instrumentation Coronal enlargement (24) and preliminary creation of a glide path are the main requisites $(25,26)$. The analysis of modifications in canal curvature after instrumentation is a reliable method to evaluate the tendency of a shaping technique to maintain the original canal anatomy or to straighten the curves (27). In this study, analysis was performed through observation of changes between preinstrumentation and post instrumentation curvature in the MB canals in the transverse axis.

Flaring the coronal portion of the root canal should be the procedure of choice in case of severe curvature, in order to facilitate the placement of files into the apical segment (28) and prevent excessive flexural stresses to the Ni-Ti instruments $(8,12)$. Compared with manual preflaring performed with stainless steel $\mathrm{K}$-file, the use of a small-size hand K-file followed by a more flexible and less tapered NiTi rotary Path File might be a less invasive and safer method to provide a glide path that better maintains the original canal anatomy (29). It permits to maintain a pathway to the full Working Length, avoiding excessive instrument binding in the canal. Hence preflaring tends to minimize procedural errors such as transportation and ledge formation. $(25,26)$

The MB canals were used because these canals are prone to iatrogenic errors (30) since they are often narrow and have accentuated curves that increase the level of instrumentation difficulty (31). If the apical preparation of the root is not centred, it might lead to blockages, perforations and ledges, resulting in inadequately cleaned canals with the likelihood of persistent apical periodontitis (32). The distal (furcal) root wall of the MB canal of a mandibular molar is thinner in teeth with long roots $(24 \mathrm{~mm})$ than in short-rooted teeth $(19 \mathrm{~mm})$, therefore perforations might occur more frequently in mandibular teeth with long roots than short-rooted teeth (33). In the present study most of the instrumented canals were transported towards the furcal (distal) aspect of the root at various intervals.

The rationale behind measurement of changes in the cross sectional area was to enable comparisons at standardized cutplanes. When compared with previous work (34), concluded that it is difficult to measure the changes in the total area of the root canal system. Our results have shown that the cross-sectional area increased at all levels.

Canal volume was used to analyse the effects of canal instrumentation on dentine removal $(34,35)$. Excessive thinning of the root can result due to over instrumentation of the root canal. In the present study, root canal instrumentation resulted in an increase in canal volume. Increased canal volume coronally increases the accessibility of irrigants to the apical-third of the canal, but the mechanical debridement might not be as effective apically as it is coronally.

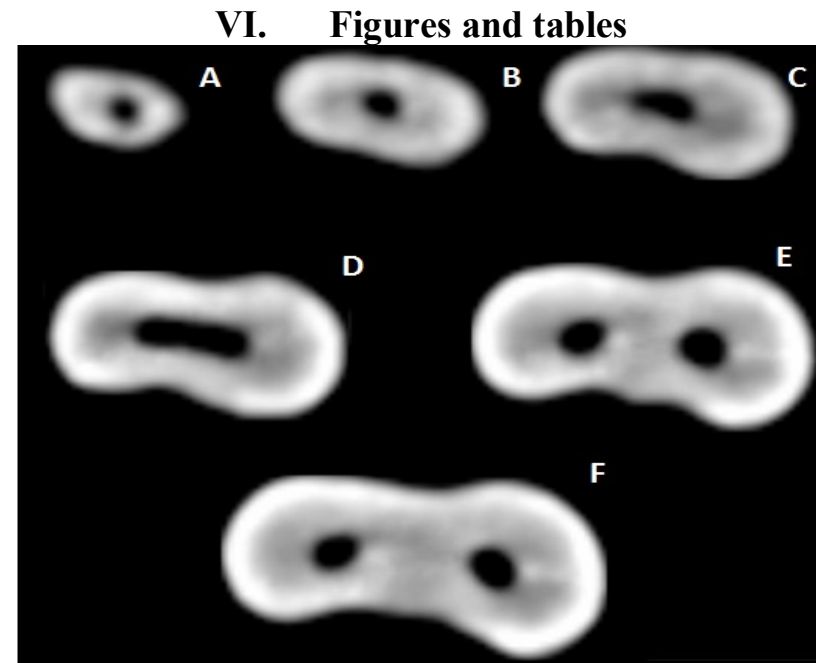

Figure 1. CBCT image showing post instrumented axial section at (A) $0 \mathrm{~mm}(\mathrm{~B}) 1 \mathrm{~mm}$ (C) $2 \mathrm{~mm}$ (D) $3 \mathrm{~mm}(\mathrm{E})$ $5 \mathrm{~mm}$ and $(\mathrm{F}) 7 \mathrm{~mm}$. 

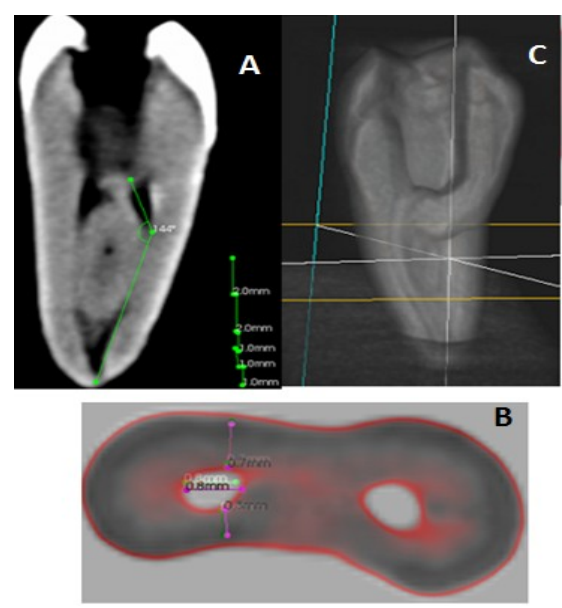

Figure 2. (A) CBCT image depicting root canal curvature at transverse section (B) Superimposition of preoperative and post-operative images in axial section (C) Image depicting the volume of the root canals.

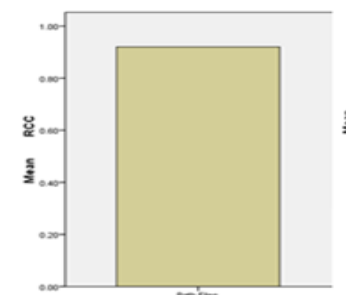

A

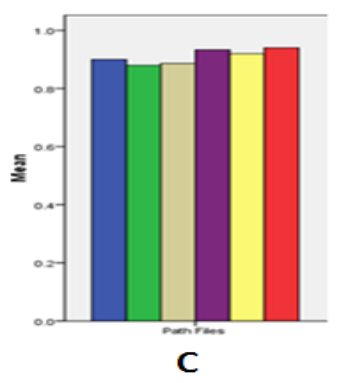

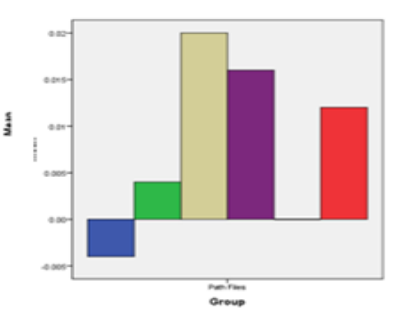

B

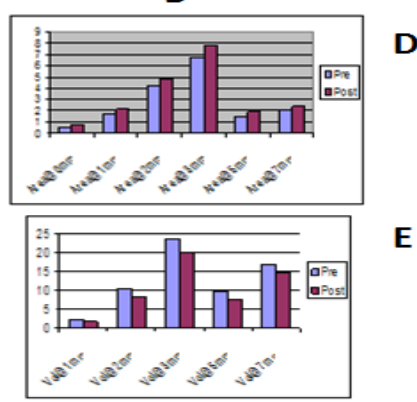

Figure 3. Bar graphs indicating the changes in the pre and post instrumented canals with respect to (A) root canal curvature (B) Canal transportation (C) Centric ability (D) Root canal cross sectional area (E) Canal volume.

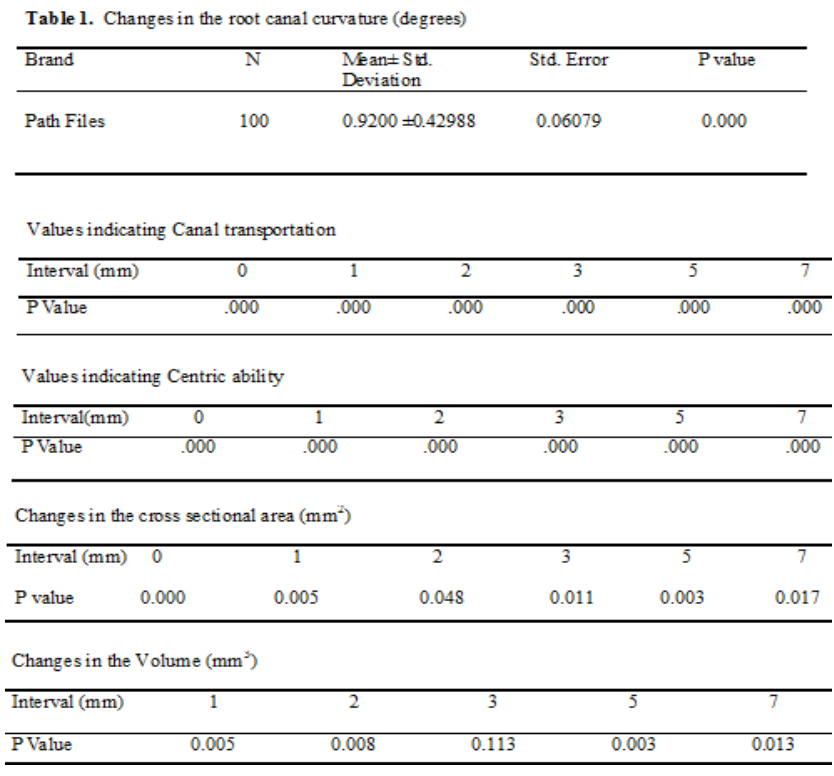




\section{Conclusion}

Under the conditions of the present study the rotary Nickel Titanium PF appeared to be suitable instruments used in clockwise rotary motion for safe and easy creation of glide path.

\section{References}

[1] Yun H, Kim SK. A comparison of the shaping abilities of 4 nickel-titanium rotary instruments in simulated root canals, Oral Surg, Oral Med, Oral Pathol, Oral Radiol, and Endod, 95(2), 2003, 228 -33.

[2] Schäfer E, Florek H. Efficiency of rotary nickel-titanium K3 instruments compared with stainless steel hand K-Flexofile. Part 1. Shaping ability in simulated curved canals, Int Endod J, 36 (3), 2003, 199 -207.

[3] Walia HM, Brantley WA, Gerstein H. An initial investigation of the bending and torsional properties of Nitinol root canal files, $J$ Endod, 14(7), 1988, 346-51.

[4] Camps JJ, Pertot WJ, Levallois B. Relationship between file size and stiffness of nickel titanium instruments. Dent Traumatol, 11(6), $1995,270-3$.

[5] Kazemi RB, Stenman E, Spangberg LS. Machining efficiency and wear resistance of nickel-titanium endodontic files. Oral Surg, Oral Med, Oral Pathol, Oral Radiol, and Endod, 81(5), 1996, 596-602.

[6] Young GR, Parashos P, Messer HH. The principles of techniques for cleaning root canals, Aust Dent J, 52(1), $2007,52-63$.

[7] Sotokawa T. An analysis of clinical breakage of root canal instruments. J Endod, 14, 1988, 75-82.

[8] Pruett JP, Clement DJ, Carnes DL Jr. Cyclic fatigue testing of nickel-titanium endodontic instruments, J Endod, 23, 1997, 77-85.

[9] Alapati SB, Brantley WA, Svec TA, Powers JM, Nusstein JM, Daehn GS. SEM observations of nickel-titanium rotary endodontic instruments that fractured during clinical use. J Endod, 31, 2005, 40-3.

[10] Parashos P, Messer HH. Rotary NiTi instrument fracture and its consequences. J Endod, 32, $2006,1031-43$.

[11] Gabel WP, Hoen M, Steiman HR, Pink FE, Dietz R. Effect of rotational speed on nickel-titanium file distorsion. $J$ Endod, 25, 1999, 752-754.

[12] Sattapan B, Palmara JE, Messer HH. Torque during canal instrumentation using rotary nickel-titanium files. $J$ Endod, 26, 2000, 156160.

[13] Kobayashi C, Yoshioka T, Suda H. A new engine driven canal preparation system with electronic canal measuring capabilities. $J$ Endod, 23, 1997, 751-54.

[14] Blum JY, Cohen P, Machtou P, Micallet JP. Analysis of forces developed during mechanical preparation of extracted teeth using Profile Ni-Ti rotary instruments. Int Endod J, 32, 199, :24-31.

[15] Peters OA, Peters CI, Schonenberg K, Barbakow F. ProTaper rotary root canal preparation: assessment of torque and force in relation to canal anatomy. Int Endod J, 36, 2003, 36:93-99.

[16] Vyver van der Peet. Creating a glide path for rotary NiTi instruments: part one Int Dent Sa, 13, 2011, 6-10.

[17] Vyver van der Peet. Creating a glide path for rotary NiTi instruments: part two Int Dent Sa, 13, 2011, 14-25.

[18] Mounce R. An excellent glide path , the road to smoother endodontics. Oral health journal, 94, 2004, 51-68

[19] West J. Manual versus Mechanical endodontic glide path. Dentistry Today, 30, 2011, 136, $138,140$.

[20] Taylor P. Cotton, DDS, Todd M. Geisler, DDS, David T. Holden, DMD, Scott A. Schwartz, DDS, and William G. Schindler. Endodontic Applications of Cone-Beam Volumetric Tomography, J Endod,33, 2007, 1121-1132.

[21] Nair MK, Nair UP. Digital and Advanced Imaging in Endodontics: A Review. J Endod, 33, 2007, 1-6.

[22] Lofthag HS, Huumonen S, Grondahl K, Grondahl HG (2007) Limited cone-beam CT and intraoral radiography for the diagnosis of periapical pathology. Oral Surg Oral Med Oral Pathol Oral Radiol Endod, 103, 2007, 114 -9.

[23] Jafarzadeh H, Abbott PV. Ledge formation: review of a great challenge in endodontics. J Endod, 33, 2007, 1155-62.

[24] Roland DD, Andelin WE, Browning DF, Hsu GH, Torabinejad M. The effect of preflaring on the rates of separation for 0.04 taper nickel titanium rotary instruments. JEndod, 28, 2002, 543-5.

[25] Berutti E, Negro AR, Lendini M, Pasqualini D. Influence of manual preflaring and torque on the failure rate of ProTaper rotary instruments. J Endod, 30, 2004, 228-30.

[26] Patiino PV, Biedma BM, Li_ebana CR, Cantatore G, Bahillo JG. The influence of a manual glide path on the separation rate of NiTi rotary instruments. J Endod, 31, 2005, 114-6.

[27] Merrett SJ, Bryant ST, Dummer PM Comparison of the shaping ability of RaCe and FlexMaster rotary nickel-titanium systems in simulated canals. J Endod, 32, 2006, 960-2.

[28] Leeb J. Canal orifice enlargement as related to biomechanical preparation. J Endod, 9, 1983, 463-70.

[29] Berutti E, Cantatore G, Castellucci A, et al .Use of nickel-titanium rotary PathFile to create the glide path: comparison with manual preflaring in simulated root canals, $J$ Endod, 35, 2009, 408-12.

[30] Abou-Rass M, Frank AL, Glick DH. The anticurvature filing method to prepare the curved root canal, J Am Dent Assoc, 101, 1980, $792-4$.

[31] Berutti E, Fedon G. Thickness of cementum/dentin in mesial roots of mandibular first molars. J Endod, 18, 1992, 545-8.

[32] Gorni FG, Gagliani MM. The outcome of endodontic retreatment: a 2-yr follow-up. J Endod, 30, $2004,1-4$.

[33] Sauaia TS, Gomes BP, Pinheiro ET, Zaia AA, Ferraz CC, Souza-Filho FJ. Microleakage evaluation of intraorifice sealing materials in endodontically treated teeth. Oral Surg Oral Med Oral Pathol Oral Radiol Endod, 102, 2006, 242-6.

[34] Peters OA, Peters CI, Schonenberger K, Barbakow F. ProTaper rotary root canal preparation: effects of canal anatomy on final shape analysed by micro CT. Int Endod J, 36, 2003, 86-92.

[35] Bergmans L, Van Cleynenbreugel J, Wevers M, Lambrechts P. A methodology for quantitative evaluation of root canal instrumentation using microcomputed tomography. Int Endod J, 34, 2001b, 390-8. 